\title{
Streptococcus pneumoniae isolated from the nasal carriage and its antibiotic susceptibility profiles in children
}

\begin{tabular}{cc}
\hline Aza Bahadeen Taha ${ }^{1 *}$ & Katan Sabir Ali $^{2}$ \\
\hline Abstract &
\end{tabular}

Background and objective: The prevalence of Streptococcus pneumoniae and resistance to antibiotics have become a public health problem in different countries of the world. This study aimed to investigate the occurrence of Streptococcus pneumoniae nasal carriage among children, and their antibiotics susceptibility profiles.

Methods: A nasal swab was obtained from 1092 healthy children aged from 6 to13 years in Erbil Parks, Kurdistan region, Iraq. The swabs were cultured on appropriate culture media to isolate Streptococcus pneumoniae and to examine their susceptibility to antibiotics. The antibiotic susceptibility testing was performed using the standard disk-diffusion method.

Results: Streptococcus pneumoniae was isolated from 224 (20.51\%) of the specimens; $57.59 \%$, and $56.25 \%$ of isolates were resistant to penicillin and ampicillin, respectively, while $3.57 \%$ and $4.46 \%$ were resistant to clarithromycin and moxifloxacin, respectively. None of the isolates had resistant to vancomycin.

Conclusion: There is a high prevalence of penicillin and another $\beta$-lactam drug resistance among isolates of Streptococcus pneumoniae from the nasal carriage of children in our region.

Keywords: Streptococcus pneumoniae; Antibiotic susceptibility; Nasal carriage; Penicillin resistance.

\section{Introduction}

Streptococcus pneumoniae ( $S$. pneumoniae) is a significant bacterial pathogen worldwide, causing serious illness, such as meningitis, bacteremia, acute otitis media, and pneumoniae. ${ }^{1}$ An estimated one million children less than 5 years old die each year from S. pneumoniae caused pneumonia. ${ }^{2}$ S. pneumoniae is a part of the normal microbial flora of the nose and pharynx, particularly among young children, and are easily transmitted, usually by droplet secretions, from person to person. ${ }^{3}$ The nasal mucosa is the first line of defense against pathogenic bacteria and permits a large and diverse community of bacterial species to asymptomatically colonies the upper respiratory tract. ${ }^{4}$ The colonization of
S. pneumoniae in the nasopharynx is believed to be an important reservoir for community spread of this pathogen and a key factor preceding pneumococcal diseases. ${ }^{5}$ S. pneumoniae asymptomatically colonizes nasal of children and it is a frequent cause of otitis media. ${ }^{6,7} \mathrm{~S}$. pneumoniae is a common nasal colonizer capable of causing lifethreatening human diseases worldwide. ${ }^{8}$ In the individual host, the colonization mainly depends on age. Several studies have shown that age younger than two years is associated with the highest carriage rate. ${ }^{9}$ The rate declines thereafter to a stable and low prevalence in adolescents. ${ }^{10}$ There were few data focused on pneumococcal carriage in both pediatric and adult population. ${ }^{11}$ For many

1 Department of Basic Sciences, College of Nursing, Hawler Medical University, Erbil, Iraq.

${ }^{2}$ Department of Medical Microbiology, College of Health Sciences, Hawler Medical University, Erbil, Iraq.

* Correspondence: aza.taha@hmu.edu.krd 
years, penicillin and antibiotics have been the mainstay of treatment for S. pneumoniae infections in developing countries, as they are both inexpensive and effective. ${ }^{1,12,13}$ Unfortunately, the rapid increase in resistance to penicillin and other antibiotics agents worldwide has made the choice of antibiotics for S. pneumoniae infections more difficult and costly. ${ }^{14-17}$ Many countries have implemented surveillance programs to monitor antibiotic resistance in $S$. pneumoniae, of which the international public health agencies have recommended the collection of resistance surveillance data for the rational choice of empiric treatments. ${ }^{18,19}$ This study aimed to investigate the occurrence of S. pneumoniae nasal carriage among children, and their antibiotics susceptibility profiles.

\section{Methods}

A cross-sectional study was carried out during the period from April 2015 to October 2016. A nasal swab was obtained from each child with a cotton swab pre-moistened with sterile normal saline, then inserted and rotated in each of the anterior nares. ${ }^{20}$ The studied population consisted of healthy children aged 6-13 years in Erbil Parks, Kurdistan region, Iraq. Ethically the permission was obtained from the child and their parents to participate in the study. All information about children was saved confidentially. The swabs were streaked immediately onto Mueller-Hinton agar (HiMedia, India) supplemented with $10 \%$ sheep blood containing $2 \mathrm{mg} / \mathrm{L}$ of crystal violet, $50 \mathrm{mg} / \mathrm{L}$ of nalidixic acid, and $2 \mathrm{mg} / \mathrm{L}$ of gentamicin, which is highly selective for $S$. pneumoniae. The plates were transported to the laboratory as soon as the collection has been verified. At the laboratory, the plates were incubated at $35^{\circ} \mathrm{C}$ in a $5 \%-10 \% \mathrm{CO}_{2}$ jar incubator for 24 hrs. The typical colonies for S. pneumoniae were selected and plated onto blood a gar plates. ${ }^{2,21}$ Hospitalized children were excluded from this study, as well as children who had received antibiotic treatment within four weeks of the nasal swab. Children who had known immunologic disorders, chronic disease, children whose parents refused to allow them to be enrolled in the study, and/or children who had current or recent invasive pneumococcal disease (pneumonia, bacteremia, and meningitis) were also excluded. ${ }^{22}$ The isolates were identified as S. pneumoniae by colony morphology, hemolysis on blood agar, and Gram stain. The identification was confirmed by optochin sensitivity and bile solubility test. ${ }^{23}$ Antibiotic susceptibility to penicillin G, ampicillin, cefuroxime, cefotaxime, ceftriaxone, ciprofloxacin, moxifloxacin, erythromycin, azithromycin, clarithromycin, and clindamycin (Oxoid, UK) were tested by the Kirby Bauer disk diffusion method. ${ }^{21,24,25}$

\section{Statistical Analysis:}

Data were analyzed using the statistical package for the social sciences (version 22). The Chi-square test was used to compare between groups. A $P$ value of $\leq 0.05$ was considered statistically significant.

\section{Results}

A total of 1092 healthy children were enrolled in this study, of whom 612 $(56.04 \%)$ were boys, and the majority of the children $(67.03 \%)$ were living in urban environments (Table 1). The percentage of $S$. pneumoniae carriage among total children was $20.51 \%$. According to age groups, the high percentage of S. pneumoniae carriage was $30.36 \%$ (68 children out of 291) among children in the age group 6 to 7 years (Table 2). The rate of $S$. pneumoniae carriage was $21.73 \%$ among boys, and it was $18.96 \%$ among girls (Table 3 ). 
Streptococcus pneumoniae isolated from .......

Zanco J. Med. Sci., Vol. 23, No. (3), December, 2019

https://doi.org/10.15218/zjms.2019.039

Table 1: Characteristics of studied children.

\begin{tabular}{llll}
\hline Characteristics & & No. & $\%$ \\
\hline Age (years) & $6-7$ & 291 & 26.65 \\
& $8-9$ & 297 & 27.20 \\
& $10-11$ & 245 & 22.44 \\
& $12-13$ & 259 & 23.72 \\
Gender & Boys & 612 & 56.04 \\
& Girls & 480 & 43.96 \\
Residency & Urban & 732 & 67.03 \\
& Rural & 360 & 32.97 \\
Total & & 1092 & 100 \\
\hline
\end{tabular}

Table 2: Distribution of children with S. pneumoniae carriage according to age.

\begin{tabular}{lcccc}
\hline Age (years) & Number of children examined & \multicolumn{2}{c}{ S. pneumoniae carriage } & $P$ value \\
& & No. & $\%$ & \\
\hline $6-7$ & 291 & 68 & 30.36 & \\
$8-9$ & 297 & 63 & 28.13 & \\
$10-11$ & 245 & 50 & 22.32 & 0.265 \\
$12-13$ & 259 & 43 & 19.20 & \\
Total & 1092 & 224 & 20.51 & \\
\hline
\end{tabular}

Table 3: S. pneumoniae carriage and gender.

\begin{tabular}{lcccc}
\hline Genders & Number of children examined & S. pneumoniae carriage & $P$ value \\
& & $\boldsymbol{N}$ & $\%$ & \\
\hline Boys & 612 & 133 & 21.73 & \\
Girls & 480 & 91 & 18.96 & 0.359 \\
Total & 1092 & 224 & 20.51 & \\
\hline
\end{tabular}


The high percentage of antibiotics resistance was $57.59 \%$ to penicillin and $56.25 \%$ to ampicillin, followed by cefuroxime $(48.21 \%)$, cefotaxime $(46.88 \%)$, and ceftriaxone $(45.09 \%)$. All $S$. pneumoniae were sensitive to vancomycin (Table 4). Children from the rural area were more likely to carry S. pneumoniae isolates resistance to penicillin $(62.30 \%)$, ampicillin $(60.66 \%)$, and cefotaxime $(62.30 \%)$ but less likely to carry an isolate resistance to moxifloxacin and azithromycin (1.64\%) and clindamycin $(3.28 \%)$. All S. pneumoniae isolated were sensitive to clarithromycin in the rural area, whereas only $4.91 \%$ were resistant in urban (Table 5).

Table 4: Antibiotics susceptibility of $S$. pneumoniae isolated from nasal carriage.

\begin{tabular}{|c|c|c|c|c|c|}
\hline \multirow{3}{*}{ Antibiotics (concentrations) } & \multicolumn{4}{|c|}{ Total number of isolated tested $=224$} & \multirow{3}{*}{$P$ value } \\
\hline & \multicolumn{2}{|c|}{ Sensitive } & \multicolumn{2}{|c|}{ Resistance } & \\
\hline & No. & $\%$ & No. & $\%$ & \\
\hline Penicillin G (10 units) & 95 & 42.41 & 129 & 57.59 & 0.107 \\
\hline Ampicillin $(10 \mu \mathrm{g})$ & 98 & 43.75 & 126 & 56.25 & 0.185 \\
\hline Cefuroxime $(30 \mu \mathrm{g})$ & 116 & 51.79 & 108 & 48.21 & 0.705 \\
\hline Cefotaxime $(30 \mu \mathrm{g})$ & 119 & 53.13 & 105 & 46.88 & 0.508 \\
\hline Ceftriaxone $(30 \mu \mathrm{g})$ & 123 & 54.91 & 101 & 45.09 & 0.298 \\
\hline Ciprofloxacin $(5 \mu \mathrm{g})$ & 192 & 85.71 & 32 & 14.29 & $<0.001$ \\
\hline Moxifloxacin $(5 \mu \mathrm{g})$ & 214 & 95.54 & 10 & 4.46 & $<0.001$ \\
\hline Erythromycin $(15 \mu \mathrm{g})$ & 189 & 84.38 & 35 & 15.63 & $<0.001$ \\
\hline Azithromycin $(15 \mu \mathrm{g})$ & 197 & 87.95 & 27 & 12.05 & $<0.001$ \\
\hline Clarithromycin $(15 \mu \mathrm{g})$ & 216 & 96.43 & 8 & 3.57 & $<0.001$ \\
\hline Clindamycin $(2 \mu \mathrm{g})$ & 209 & 93.30 & 15 & 6.70 & $<0.001$ \\
\hline Vancomycin $(30 \mu \mathrm{g})$ & 224 & 100 & 0 & 0 & ND \\
\hline
\end{tabular}

$\mathrm{ND}=$ Not done

Table 5: Antibiotics resistance of $S$. pneumoniae isolated from urban and rural.

\begin{tabular}{|c|c|c|c|c|c|c|c|}
\hline \multirow{2}{*}{ Antibiotics (concentrations) } & \multicolumn{2}{|c|}{ Urban $(n=163)$} & \multicolumn{2}{|c|}{ Rural ( $n=61)$} & \multicolumn{2}{|c|}{ Total $(n=224)$} & \multirow{2}{*}{$P$ value } \\
\hline & No. & $\%$ & No. & $\%$ & No. & $\%$ & \\
\hline Penicillin G (10 units) & 91 & 55.83 & 38 & 62.30 & 129 & 57.59 & 0.654 \\
\hline Ampicillin $(10 \mu \mathrm{g})$ & 89 & 54.60 & 37 & 60.66 & 126 & 56.25 & 0.669 \\
\hline Cefuroxime $(30 \mu \mathrm{g})$ & 81 & 49.69 & 27 & 44.26 & 108 & 48.21 & 0.666 \\
\hline Cefotaxime $(30 \mu \mathrm{g})$ & 67 & 41.10 & 38 & 62.30 & 105 & 46.88 & 0.986 \\
\hline Ceftriaxone $(30 \mu \mathrm{g})$ & 75 & 46.01 & 26 & 42.62 & 101 & 45.09 & 0.777 \\
\hline Ciprofloxacin $(5 \mu \mathrm{g})$ & 24 & 14.72 & 8 & 13.11 & 32 & 14.29 & 0.790 \\
\hline Moxifloxacin $(5 \mu \mathrm{g})$ & 9 & 5.52 & 1 & 1.64 & 10 & 4.46 & 0.227 \\
\hline Erythromycin $(15 \mu \mathrm{g})$ & 23 & 14.11 & 12 & 19.67 & 35 & 15.63 & 0.388 \\
\hline Azithromycin $(15 \mu \mathrm{g})$ & 26 & 15.95 & 1 & 1.64 & 27 & 12.05 & 0.007 \\
\hline Clarithromycin $(15 \mu \mathrm{g})$ & 8 & 4.91 & 0 & 0 & 8 & 3.57 & 0.856 \\
\hline Clindamycin $(2 \mu \mathrm{g})$ & 13 & 7.98 & 2 & 3.28 & 15 & 6.70 & 0.237 \\
\hline Vancomycin $(30 \mu \mathrm{g})$ & 0 & 0 & 0 & 0 & 0 & 0.00 & ND \\
\hline
\end{tabular}




\section{Discussion}

Colonization of nasal is a dynamic process with a turnover of new strains of S. pneumoniae. ${ }^{26}$ The percentage of nasal carriage of $S$. pneumoniae in children as reported in this study was lower than the study reported in Vietnamese children. $^{2,8}$ The percentage of nasal carriage of S. pneumoniae varied from $9 \%$ in Singapore to $43 \%$ in India among children. ${ }^{22}$ Accordingly, it is has been reported that the anterior nasal swabs are easier to do in younger children and the method was to be as sensitive as a nasopharyngeal aspiration but, might affect lower carriage rates in some countries. ${ }^{2,22,27}$ In the present study, the high rate of nasopharyngeal carriage of $S$. pneumoniae was observed among children aged 6 to 7 years than other age groups. The immunological developments of cellular and humoral responses to S. pneumoniae capsular polysaccharide contribute towards a much lower incidence of pneumococcal disease in older children than in young children. ${ }^{12,18,28}$ On the other hand, the study was observed that the rate of $S$. pneumoniae carriage more common in boys compared to the girls; this may be due to the boys in our culture is more exposed to the external environment. The prevalence of antibiotics resistance has been studied in different countries in the world. In the present study, the high rate of penicillin and ampicillin resistance was observed among $S$. pneumoniae nasal carriage isolates that lower than reported in Taiwan, Korea, Sri Lanka, Vietnam, and Saudi Arabia (50\%). ${ }^{22}$ Moreover, it has been detected that $S$. pneumoniae is a naturally transformable organism, selective pressure of any antibiotic may facilitate incorporation of extrachromosomal DNA encoding various antibiotic resistance mechanisms. ${ }^{18,29}$ Therefore, penicillin resistance in clinical isolates of $S$. pneumoniae has become an important problem, ${ }^{2,30,31}$ and strategies to prevent the emergence of clinically significant diseases caused by
S. pneumoniae resistance to antibiotics in this region will be needed. Penicillin and ampicillin are widely used in our region and are available over the counter at a suitable price, particularly in subclinical pharmacy that used randomly without physician prescription may contribute to increasing penicillin resistance among $S$. pneumoniae strains. Furthermore, it has been found that the $S$. pneumoniae strains with both penicillin and other $\beta$-antibiotics resistance appear to be increasing worldwide, although rates may vary depending on the location. ${ }^{20}$ With limited use of new antibiotics such as azithromycin, clarithromycin, clindamycin, and vancomycin for treatment of S. pneumoniae, the study reported a low level of resistance to these antibiotics. The rate of urban children to penicillin and ampicillin resistance of $S$. pneumoniae isolates was significantly lower than the rate obtained in children of the rural area; this was in agreement with a study has been reported in Southern Vietnam of which the use of the antibiotic in rural children was lower than in urban children. $^{32,33}$ The increase of antibiotic resistance in $S$. pneumoniae is attributed to several factors, including socio-cultural and economic factors and differences in regulatory practices, particularly antibiotic consumption. ${ }^{34,35}$ European studies have shown that variations of antibiotic consumption are well correlated to S. pneumoniae rates at the country level. Therefore, antibiotic consumption should be considered according to the volume and the pattern use. ${ }^{36-38}$ It has been found that the emergence of antibiotics resistant clones of $S$. pneumoniae appears to be delayed in rural areas compared with urban areas, but clonal spread, combined with the use of antibiotics, is likely to account for carriage rates of antibiotics resistant strains that were similar to urban areas. $^{20}$

\section{Conclusion}

The high rate of $S$. pneumoniae nasal 
carriage among children that could serve as reservoirs for the transmission to the community and cause disease. Meanwhile, the high rate of $S$. pneumoniae antibiotics susceptibility was observed for vancomycin, clarithromycin, moxifloxacin, and clindamycin. There are still a number of other factors contributing to the spread of resistant S. pneumoniae. Therefore, further studies of antibiotics resistance will be needed.

\section{Competing interests}

The authors declare no competing interests.

\section{References}

1. Benbachir M, Elmdaghri $\mathrm{N}$, Belabbes $\mathrm{H}$, Haddioui $G$, Benzaid H, Zaki B. Eleven-year surveillance of antibiotic resistance in Streptococcus pneumoniae in Casablanca (Morocco). Microb Drug Resist 2012; 18(2):157-60.

2. Parry CM, Diep TS, Wain J, Hoa NTT, Gainsborough M, Nga D, et al. Nasal carriage in Vietnamese children of Streptococcus pneumoniae resistant to multiple antimicrobial agents. Antimicrob Agents Chemother 2000; 44(3):484-8.

3. O'BRIEN KL, Nohynek H, Group WPVTCW. Report from a WHO Working Group: standard method for detecting upper respiratory carriage of Streptococcus pneumoniae. Pediatr Infect Dis 2003; 22(2):e1-11.

4. Charlson ES, Bittinger $\mathrm{K}$, Haas AR, Fitzgerald AS, Frank I, Yadav A, et al. Topographical continuity of bacterial populations in the healthy human respiratory tract. Am J Respir Crit Care Med 2011; 184(8):957-63.

5. Petraitiene S, Alasevicius $\mathrm{T}$, Staceviciene I, Vaiciuniene D, Kacergius T, Usonis V. The influence of Streptococcus pneumoniae nasopharyngeal colonization on the clinical outcome of the respiratory tract infections in preschool children. BMC Infect Dis 2015; 15:403.

6. Abdullahi O, Karani A, Tigoi CC, Mugo D, Kungu S, Wanjiru E, et al. The prevalence and risk factors for pneumococcal colonization of the nasopharynx among children in Kilifi District, Kenya. PloS One 2012; 7(2):e30787.

7. Laufer AS, Metlay JP, Gent JF, Fennie KP, Kong $\mathrm{Y}$, Pettigrew MM. Microbial communities of the upper respiratory tract and otitis media in children. MBio 2011; 2(1):e00245-10.

8. Bogaert D, de Groot R, Hermans P. Streptococcus pneumoniae colonisation: the key to pneumococcal disease. Lancet Infect Dis 2004; 4(3):144-54.
9. Trzciński K, Li Y, Weinberger DM, Thompson CM, Cordy D, Bessolo A, et al. Effect of serotype on pneumococcal competition in a mouse colonization model. M Bio 2015; 6(5):e00902-15.

10. Bogaert D, van Belkum A, Sluijter M, Luijendijk A, de Groot $R$, Rümke $H$, et al. Colonisation by Streptococcus pneumoniae and Staphylococcus aureus in healthy children. Lancet 2004; 363(9424):1871-2.

11. Regev-Yochay G, Raz M, Dagan R, Porat N, Shainberg B, Pinco E, et al. Nasopharyngeal carriage of Streptococcus pneumoniae by adults and children in community and family settings. Clin Infect Dis 2004; 38(5):6329.

12. Wright AK, Ferreira DM, Gritzfeld JF, Wright $A D$, Armitage $\mathrm{K}$, Jambo $\mathrm{KC}$, et al. Human nasal challenge with Streptococcus pneumoniae is immunising in the absence of carriage. PLoS Pathog 2012; 8(4):e1002622.

13. Magalhães APGdO, Pinto AdS. Antimicrobial resistance and serotyping of Streptococcus pneumoniae isolated from pediatric patients in Belo Horizonte, MG, Brazil. BJM 2003; 34(3):210 -2 .

14. Alanis AJ. Resistance to antibiotics: are we in the post-antibiotic era? Arch Invest Med 2005; 36(6):697-705

15. Laxminarayan R, Duse A, Wattal C, Zaidi AK, Wertheim HF, Sumpradit $N$, et al. Antibiotic resistance - the need for global solutions. Lancet Infect Dis 2013; 13(12):1057-98.

16. Weber FT, Dias C, Costa Md. Antimicrobial susceptibility of Streptococcus pneumoniae and genotypic characterization of erythromycinresistant strains in Porto Alegre, Brazil. BJM 2010; 41(1):1-5.

17. Naba MR, Araj GF, Baban TA, Tabbarah ZA, Awar GN, Kanj SS. Emergence of fluoroquinolone-resistant Streptococcus pneumoniae in Lebanon: a report of three cases. J Infect Public Health 2010; 3(3):113-7.

18. Hortal M, Lovgren M, De la Hoz F, Agudelo C, Brandileone $\mathrm{M}$, Camou $\mathrm{T}$, et al. Antibiotic resistance in Streptococcus pneumoniae in six Latin American countries: 1993-1999 surveillance. Microb Drug Resist 2001; 7(4):391401.

19. El Ashkar S, Osman M, Rafei R, Mallat H, Achkar $M$, Dabboussi $F$, et al. Molecular detection of genes responsible for macrolide resistance among Streptococcus pneumoniae isolated in North Lebanon. J Infect Public Health 2017; 10(6):745-8.

20. Schultsz C, Campbell JI, Chau NVV, Diep TS, Hoang NVM, Nga TTT, et al. Changes in the nasal carriage of drug-resistant Streptococcus pneumoniae in urban and rural Vietnamese schoolchildren. Trans R Soc Trop Med Hyg 2007; 101(5):484-92. 
21. Villanova P. Performance standards for antimicrobial disk susceptibility tests. NCCLS Approved Standard 7th ed NCCLS 2000; 20:M2A7.

22. Lee NY, Song J-H, Kim S, Peck KR, Ahn K-M, Lee S-I, et al. Carriage of antibiotic-resistant pneumococci among Asian children: a multinational surveillance by the Asian Network for Surveillance of Resistant Pathogens (ANSORP). Clin Infect Dis 2001; 32 (10):1463-9.

23. Kellogg JA, Bankert DA, Elder CJ, Gibbs JL, Smith MC. Identification of Streptococcus pneumoniae revisited. J Clin Microbiol 2001; 39(9):3373-5.

24. Jorgensen JH, Turnidge JD. Susceptibility test methods: dilution and disk diffusion methods. Manual of Clinical Microbiology $11^{\text {th }}$ ed. Washington, DC:ASM Press; 2015. P. 1253-73.

25. Reller LB, Weinstein $M$, Jorgensen $\mathrm{JH}$, Ferraro MJ. Antimicrobial susceptibility testing: a review of general principles and contemporary practices. CID 2009; 49(11):1749-55.

26. Margolis E, Yates A, Levin BR. The ecology of nasal colonization of Streptococcus pneumoniae, Haemophilusinfluenzae and Staphylococcus aureus: the role of competition and interactions with host's immune response. BMC Microbiol 2010; 10(1):1.

27. Syrjänen RK, Kilpi TM, Kaijalainen TH, Herva EE, Takala AK. Nasopharyngeal carriage of Streptococcus pneumoniae in Finnish children younger than 2 years old. J Infect Dis 2001; 184 (4):451-9.

28. van der Poll T, Opal SM. Pathogenesis, treatment, and prevention of pneumococcal pneumonia. Lancet 2009; 374(9700):1543-56.

29. Johnston C, Caymaris S, Zomer A, Bootsma HJ, Prudhomme M, Granadel C, et al. Natural genetic transformation generates a population of merodiploids in Streptococcus pneumoniae. PLoS Genet 2013; 9(9):e1003819.

30. Ma X, Zhao R, Ma Z, Yao K, Yu S, Zheng Y, et al. Serotype distribution and antimicrobial resistance of Streptococcus pneumoniae isolates causing invasive diseases from Shenzhen Children's Hospital. PloS One 2013; 8(6):e67507.

31. Warda K, Oufdou K, Zahlane K, Bouskraoui M. Antibiotic resistance and serotype distribution of nasopharyngeal isolates of Streptococcus pneumoniae from children in Marrakech region (Morocco). J Infect Public Health 2013; 6(6):47381.

32. Quagliarello A, Parry CM, Hien TT, Farrar JJ. Factors associated with carriage of penicillinresistant Streptococcus pneumoniae among Vietnamese children: a rural-urban divide. J Health Popul Nutr 2003; 21(4):316-24.

33. Thummeepak R, Leerach $N$, Kunthalert D, Tangchaisuriya $U$, Thanwisai A, Sitthisak S. High prevalence of multi-drug resistant Streptococcus pneumoniae among healthy children in Thailand. $\mathrm{J}$ Infect Public Health 2015; 8(3):274-81.

34. Harbarth S, Albrich W, Brun-Buisson C. Outpatient antibiotic use and prevalence of antibiotic-resistant pneumococci in France and Germany: sociocultural perspective. Emerg Infect Dis 2002; 8(12):1460-7.

35. Taha AB, Hama KH, Ismail IB. Assessment of Antibiotics Misuse among People in Erbil City. Kufa Journal for Nursing Sciences 2014; 4(3):2335.

36. Ehara N, Fukushima K, Kakeya $H$, Mukae $H$, Akamatsu S, Kageyama A, et al. A novel method for rapid detection of Streptococcus pneumoniae antigen in sputum and its application in adult respiratory tract infections. J Med Microbiol 2008; 57(7):820-6.

37. García-Rey C, Aguilar L, Baquero F, Casal J, Dal-Ré R. Importance of local variations in antibiotic consumption and geographical differences of erythromycin and penicillin resistance in Streptococcus pneumoniae. J Clin Microbiol 2002; 40(1):159-64.

38. Coenen S, Ferech M, Haaijer-Ruskamp FM, Butler CC, Vander Stichele RH, Verheij TJ, et al. European Surveillance of Antimicrobial Consumption (ESAC): quality indicators for outpatient antibiotic use in Europe. Qual Saf Health Care 2007; 16(6):440-5. 